\title{
Regional patterns of brain 2-DG uptake produced in mice by electrical stimulation of the septum, hypothalamus, or entorhinal cortex: Relation to functional neural pathways involved in memory mechanisms
}

\author{
JAMILA SIF \\ University of El Jadida, El Jadida, Morocco \\ CLAUDE MESSIER \\ University of Ottawa, Ottawa, Ontario, Canada \\ and \\ MARTINE MEUNIER and CLAUDE DESTRADE \\ Université de Bordeaux, Talence, France
}

\begin{abstract}
The regional pattern of brain 2-DG uptake was studied in different groups of mice that received electrical stimulation of the medial septum (MS), dorsomedial hypothalamus (DMH), or lateral entorhinal cortex (LEC). Site selection was based on the findings of previous experiments, in which there was an improvement in long-term retention performance following MS stimulation when applied during the first $60 \mathrm{sec}$ of posttraining, following LEC stimulation (when applied 15-60 min posttraining), and following DMH stimulation (when applied any time within the first 60 min of posttraining). The global comparison of the patterns of stimulation-induced increases in 2-DG labeling showed that MS stimulation induced specific increases in 2-DG labeling predominantly in the hippocampal formation, whereas DMH stimulation produced increased labeling in the caudate putamen, the mediodorsal thalamus, and the entorhinal cortex. Globally, LEC stimulation produced a large cortical activation, and more particularly, it induced a specific activation of the parietal cortex. Perforant-path lesions suppressed the LEC-stimulation-induced labeling in the hippocampus but did not alter the increased labeling in the amygdala and in the cortical areas. As with previous data obtained from experiments combining training and 2-DG labeling, the functional neural networks involved in these differential labeling patterns are discussed in terms of their possible implication for early or late phases of memory processing.
\end{abstract}

Electrical stimulation of discrete areas of the brain has been used extensively as a tool to examine the involvement of certain brain structures in memory processes (Berman, 1991; Destrade, Gauthier, \& Sif, 1985; Gold, Zornetzer, \& McGaugh, 1974; Huston, Mueller, \& Mondadori, 1977; Kesner, 1982; Kesner \& Wilburn, 1974). In the consolidation paradigm, the electrical stimulation is applied during the posttraining interval and the resulting facilitation or disruption of retention is usually interpreted as an indication of the involvement of the stimu-

This research was supported by DGA Grant 92.158 from the Direction des Recherches Études et Techniques, and grants from the CNRS, the University of Bordeaux I, and the Conseil Général d'Aquitaine. C.M. was supported by a Human Frontier Science Program research fellowship. We thank Thomas Durkin for his help and comments in writing this manuscript, and J. Ducout and A. M. Perret for technical assistance. Correspondence and requests for reprints should be addressed to C. Destrade, Laboratoire de Neurosciences Comportementales et Cognitives, URA CNRS 339, Université de Bordeaux I, 33405 Talence Cedex, France. lated structure in memory consolidation (Bloch, 1970; Gold \& McGaugh, 1975; Huston et al., 1977; McGaugh, 1966; Routtenberg, 1975). Consolidation refers both to the perseveration of the activity of neural pathways elicited by the various aspects of a learning situation (Glickman, 1961; Hebb, 1949) and to the gradual incorporation of new stable patterns of neural activity consecutive to the perseveration phase (McGaugh, 1966). More recently, some authors have proposed that memory consolidation may involve not only the strengthening of new information but also the incorporation of other contextual information present in the learning situation (Izquierdo, 1989; Squire, 1987). This more complex view of memory consolidation implies that several processes may take place during the period that follows a learning experience. It is conceivable that the early period of memory consolidation involves the registration and temporary storage of the new elements present in a learning situation, while the late period involves comparative and integrative processes that lead to a more permanent trace. 
We have previously demonstrated in mice that electrical subconvulsive stimulation of various limbic regions, following partial training in a barpressing appetitive task, produced a noncontingent improvement in long-term retention performance (for a review, see Destrade et al., 1985). For instance, we have shown that posttraining stimulation of the medial septum (MS) improved retention performance when administered during the first $60 \mathrm{sec}$ after training (Galey \& Jaffard, 1992; Galey, Jeantet, Destrade, \& Jaffard, 1983). In contrast, the stimulation of a cortical structure, the lateral entorhinal cortex (LEC), improved retention performance only when administered between 15 and $60 \mathrm{~min}$ after training (Gauthier, Destrade, \& Soumireu-Mourat, 1982), and this improvement persisted after the perforant path had been lesioned (Gauthier \& Destrade, 1984). On the other hand, posttraining stimulation of the dorsomedial hypothalamus $(\mathrm{DMH})$ improved retention when administered at any time during the first $60 \mathrm{~min}$ following training (Destrade, 1982).

These results suggested to us that the distinct temporal gradients of the memory improvement observed following the electrical stimulation of these different structures reflected the differential temporal sequence of intervention of these subcortical and cortical areas during early and late memory processes (Destrade et al., 1985).

To further test this hypothesis, we examined, in nontrained animals, the effects of the electrical stimulation of the MS, the DMH, and the LEC on the patterns of relative 2-DG uptake in subcortical and cortical structures in order to identify the brain regions activated by this treatment. These experiments were completed by studying the effect of perforant-path lesions on the metabolic changes produced by the electrical stimulation of the LEC.

\section{METHOD}

\section{Subjects}

Ten-week-old male BALB/c JIco mice (IFFA-CREDO, Lyon, France), weighing 27-30 $\mathrm{g}$ at the start of the experiment, were used. Throughout the experiment, the mice were maintained on a 12:12-h dark:light cycle (lights on at 7 a.m.). All animals were given ad-lib access to food and water.

\section{Surgery}

The animals were anesthetized with sodium thiopental $(90 \mathrm{mg} /$ $\mathrm{kg}$ ). A polyethylene catheter (Biotrol Pharma, Paris; $0.70 \mathrm{~mm}$ outer diam; $0.30 \mathrm{~mm}$ inner diam) was inserted and secured in the jugular vein. Patency of the cannula was maintained with heparinized $0.9 \%$ saline. A bipolar electrode made of two twisted strands of $0.09-\mathrm{mm}$ insulated platinum wire was then stereotaxically implanted unilaterally in the various structures. The same electrode was used both for recording and for stimulating. An indifferent electrode consisted of a silver wire secured in the neck muscles. The electrolytic lesions of the perforant path were made by passing an anodal high-frequency current $(30 \mathrm{sec}, 500 \mathrm{KHz}, 0.05 \mathrm{~mA})$ through the tip of an epoxylite-coated stainless-steel electrode $(0.35-\mathrm{mm}$ diam, baretip $0.1 \mathrm{~mm})$ stereotaxically lowered into the structure of the brain ipsilateral to the implanted electrode. The coordinates from bregma were as follows: MS: $+0.7 \mathrm{~mm}$ anteroposterior plane (AP), $0.0 \mathrm{~mm}$ lateral to the midline (L), and $3.6 \mathrm{~mm}$ below the surface of the skull (V); DMH: $-0.8 \mathrm{~mm} \mathrm{AP,} \pm 0.3 \mathrm{~mm}$
$\mathrm{L},-5.3 \mathrm{~mm} \mathrm{~V}$; LEC: $-3.0 \mathrm{~mm} \mathrm{AP,} \pm 3.0 \mathrm{~mm} \mathrm{~L},-4.9 \mathrm{~mm} \mathrm{~V}$; and perforant path: $-3.6 \mathrm{~mm} \mathrm{AP,} \pm 3.0 \mathrm{~mm} \mathrm{~L},-2.2 \mathrm{~mm} \mathrm{~V}$. In all cases, the incisor bar was level with the interaural line. In the case of the LEC, the electrode was implanted at an angle of $12^{\circ}$ to the midsagittal plane because this structure has an extremely lateral location.

\section{Procedure}

One week after surgery, the individual current intensity to be used in stimulation experiments was determined using a previously described procedure (Gauthier \& Destrade, 1984). Experiments were carried out between 9 a.m. and 1 p.m. The animals were given a single daily session consisting of a 4 -sec unilateral stimulation (sinewave $=100 \mathrm{~Hz}, 200 \mathrm{msec}$ on, $200 \mathrm{msec}$ off) of the implanted structure in order to determine their individual afterdischarge (AD) thresholds. During the 200-msec-off interval, the EEG was continuously recorded through the bipolar stimulating electrode. AD thresholds were determined by starting with a 10- $\mu \mathrm{A}$ (peak- peak) current and increasing the current intensity in $15-\mu \mathrm{A}$ increments each successive day until ADs were elicited. As a function of the structure, the AD threshold ranged between 50 and $100 \mu \mathrm{A}$. The current intensities used for each animal in the present experiment were one half of the individually determined $A D$ values (DMH: $30 \mu \mathrm{A} \pm 2.7 \mu \mathrm{A}$ [mean value \pm SEM]; MS: $45 \mu \mathrm{A} \pm$ $3.2 \mu \mathrm{A} ; \mathrm{LEC}: 45 \mu \mathrm{A} \pm 4.2 \mu \mathrm{A})$. During the 5 min preceding the injection of 2-DG and the $35 \mathrm{~min}$ following its injection, electrical stimulation was delivered continuously for $4-\mathrm{sec}$ periods $(100 \mathrm{~Hz}$, $200 \mathrm{msec}$ on, $200 \mathrm{msec}$ off), which were interspersed with 4-secoff periods (when no electrical stimulation was delivered). The EEG for each animal showed that no ADs were present. Three control animals were implanted with electrodes in either the DMH, the MS, or the LEC, but no current was passed.

The mice were injected through the jugular-vein catheter with a solution of $0.1 \mathrm{ml}$ of (1-14C)2-deoxyglucose (Commissariat à l'Energie Atomique, Paris; specific activity: $46 \mathrm{mCi} / \mathrm{mmole}$ in $5 \%$ ethanol) diluted in $0.9 \mathrm{ml}$ of a sterile saline solution. The injection volume (approx. $0.1 \mathrm{ml}$, adjusted according to the animal's weight) resulted in the administration of $15 \mu \mathrm{Ci}$ per $100 \mathrm{~g}$ of body weight. Forty min after the injection, the animals were decapitated and the electrode withdrawn. The animals' brains were rapidly removed and then frozen in liquid nitrogen and stored at $-80^{\circ} \mathrm{C}$. Twenty $-\mu \mathrm{m}$ frontal or sagittal sections were cut in a cryostat at $-20^{\circ} \mathrm{C}$, and were then placed on coverslips and dried rapidly on a hot plate at $50^{\circ} \mathrm{C}$. They were subsequently exposed, together with a set of calibrated Amersham standards (CRF 10, carbon 14 polymer sources; concentration range: $40-1,069 \mathrm{nCi} / \mathrm{g}$ ) on Kodak Definix Medical films for 10 days. Adjacent sections were air-dried and thionin stained for histological identification of structures on the autoradiographs.

The autoradiographs were analyzed by quantitative densitometry with a Biocom 200 (Les Ulis, France) computerized image processing system with the RAG 200 software package. Twenty-seven brain regions were anatomically defined according to Lehman (1974). The mean optical density of each structure was measured bilaterally using a minimum of four consecutive sections in each brain. The value for each structure was then expressed as the ratio of the optical density of the particular structure and the mean optical density of the corpus callosum within the same brain used as a reference. It was determined that there was no significant difference between any of the groups in labeling in the corpus callosum (see Table 1; Kruskal-Wallis $H=4.04$, n.s.). This is particularly important, since there are reports of changes in the incorporation of 2-DG into white matter when animals receive certain drugs (Porrino \& Crane, 1990). Therefore, this optical-density ratio was taken as a measure of the relative metabolic activity of the particular structure. The mean 2-DG-uptake ratios contributed by each animal in a group were averaged to give the final statistics. MannWhitney U-tests were used to assess statistical differences between the groups. Optical-density ratios, which are a linear function of 
Table 1

Calculated Isotope Content in the Corpus Callosum of Unstimulated (A), DMH-Stimulated (B), MS-Stimulated (C), and LEC-Stimulated (D) Animals, and of LEC-Stimulated Animals With a Unilateral Perforant-Path Lesion (E)

\begin{tabular}{|c|c|c|c|c|c|c|c|c|c|c|}
\hline & \multicolumn{10}{|c|}{ Group } \\
\hline & \multicolumn{2}{|c|}{$\begin{array}{c}\mathrm{A} \\
(n=3)\end{array}$} & \multicolumn{2}{|c|}{$\begin{array}{c}\mathrm{B} \\
(n=3)\end{array}$} & \multicolumn{2}{|c|}{$\begin{array}{c}\mathrm{C} \\
(n=4)\end{array}$} & \multicolumn{2}{|c|}{$\begin{array}{c}\mathrm{D} \\
(n=5)\end{array}$} & \multicolumn{2}{|c|}{$\begin{array}{c}\mathrm{E} \\
(n=3)\end{array}$} \\
\hline & $M$ & $S E M$ & $M$ & SEM & $M$ & SEM & $M$ & SEM & $M$ & $S E M$ \\
\hline 2-DG & 180.4 & 7.7 & 202.0 & 9.8 & 198.4 & 8.2 & 201.6 & 8.1 & 201.4 & 11.3 \\
\hline
\end{tabular}

local cerebral glucose utilization (Sharp, Kilduff, Bzoegchami, Heller, \& Ryan, 1983), allow a comparison between animals in the same physiological conditions and tend to eliminate errors due to differences in amount of injected isotope, section thickness, film exposure, and development time. An additional criterion, which was added as a determinant of whether a difference between two groups was significant, was that the lowest ratio of the stimulated group had to be greater than the highest ratio of the control group by at least 0.2 units. This additional criterion produces more conservative decisions and effectively increases the alpha level for the comparisons.
It is important to note that relative metabolic activity as defined above is not equivalent to the local cerebral glucose utilization measure (Sokoloff et al., 1977). Two main shortcomings of the relative metabolic activity method are the reduced accuracy in the estimate of metabolic changes and the absence of controls for the variability of some parameters, such as the kinetics of glucose transport between, and metabolism in, different physiological compartments (for a discussion, see Destrade, Messier, Bontempi, Sif, \& Jaffard, 1992; Maxwell \& Fink, 1988). Nonetheless, the relative metabolic activity method can be used to detect large changes that result either from electrical stimulation of brain structures (Brutus et al., 1984; Maxwell \& Fink, 1988; Sif, Meunier, Messier, Calas, \& Destrade, 1989; Watson, Edinger, \& Siegel, 1983; Watson, Siegel, \& Siegel, 1985; Watson, Troiano, et al., 1983; Watson, Troiano, Poulakos, Weiner, \& Siegel, 1982) or from behavioral procedures (Bontempi, Sif, Jaffard, \& Destrade, 1991; Catarelli, Astic, \& Kauer, 1989; Dunn, 1986; Gonzalez-Lima, 1989; Gonzalez-Lima, Finkenstaedt, \& Ewert, 1989; Horster et al., 1989; Matsunami, Kawashima, \& Satake, 1989; Sarter, Bodewitz, \& Steckler, 1989; Sif et al., 1991). One major advantage of the relative metabolic activity method is that it can provide useful information on functional metabolic changes in freely moving unanesthetized animal preparations that are not compatible with all aspects of the cerebral local glucose utilization method (Destrade et al., 1992).

Table 2

Relative 2-DG Uptake Following Medial Septum and Dorsomedial Hypothalamus Stimulation

\begin{tabular}{|c|c|c|c|c|c|c|c|c|c|c|c|c|}
\hline \multirow[b]{3}{*}{ Structure } & \multicolumn{4}{|c|}{ Unstimulated Controls } & \multicolumn{4}{|c|}{ DMH Stimulation } & \multicolumn{4}{|c|}{ MS Stimulation } \\
\hline & \multicolumn{2}{|c|}{ Ipsi } & \multicolumn{2}{|c|}{ Contra } & \multicolumn{2}{|c|}{ Ipsi } & \multicolumn{2}{|c|}{ Contra } & \multicolumn{2}{|c|}{ Ipsi } & \multicolumn{2}{|c|}{ Contra } \\
\hline & $M$ & $S E M$ & $M$ & $S E M$ & $M$ & $S E M$ & $M$ & $S E M$ & $M$ & $S E M$ & $M$ & $S E M$ \\
\hline Amygdala & 1.26 & 0.05 & 1.27 & 0.06 & $3.24^{\mathrm{a}}$ & 0.17 & 1.34 & 0.09 & 1.86 & 0.07 & 1.93 & 0.09 \\
\hline Caudate putamen & 1.42 & 0.06 & 1.43 & 0.07 & 2.26 & 0.07 & 2.27 & 0.10 & 1.49 & 0.02 & 1.47 & 0.06 \\
\hline Diagonal band & 1.43 & 0.06 & 1.40 & 0.09 & $3.97^{\mathrm{a}}$ & 0.18 & 1.78 & 0.10 & 4.02 & 0.30 & 3.95 & 0.27 \\
\hline Lateral septum & 1.22 & 0.06 & 1.19 & 0.03 & $3.38^{\mathrm{a}}$ & 0.06 & 1.64 & 0.08 & 3.29 & 0.21 & 3.13 & 0.28 \\
\hline Medial septum & 1.43 & 0.04 & 1.43 & 0.04 & 1.53 & 0.12 & 1.53 & 0.12 & 4.87 & 0.43 & 4.87 & 0.43 \\
\hline Mammillary bodies & 2.07 & 0.11 & 2.07 & 0.11 & 4.00 & 0.10 & 4.00 & 0.10 & 3.89 & 0.31 & 3.89 & 0.31 \\
\hline Stria terminalis & 1.27 & 0.07 & 1.25 & 0.06 & $4.24^{\mathrm{a}}$ & 0.08 & 1.28 & 0.09 & 1.95 & 0.07 & 1.92 & 0.06 \\
\hline Subiculum & 1.32 & 0.05 & 1.24 & 0.06 & $2.08^{b}$ & 0.08 & 1.50 & 0.09 & 2.53 & 0.20 & 2.45 & 0.09 \\
\hline \multicolumn{13}{|l|}{ Hypothalamus } \\
\hline Dorsomedial & 1.25 & 0.09 & 1.20 & 0.04 & $4.70^{\mathrm{a}}$ & 0.10 & 1.52 & 0.10 & 1.46 & 0.08 & 1.44 & 0.10 \\
\hline Lateral & 1.29 & 0.04 & 1.25 & 0.04 & $4.73^{\mathrm{a}}$ & 0.08 & 1.34 & 0.10 & 1.77 & 0.11 & 1.78 & 0.11 \\
\hline Ventromedial & 1.24 & 0.05 & 1.23 & 0.06 & $4.79^{\mathrm{a}}$ & 0.10 & 1.50 & 0.13 & 1.24 & 0.09 & 1.14 & 0.05 \\
\hline \multicolumn{13}{|l|}{ Thalamus } \\
\hline Anteromedial & 2.01 & 0.10 & 1.98 & 0.07 & 2.52 & 0.10 & 2.49 & 0.17 & 3.18 & 0.28 & 3.09 & 0.22 \\
\hline Mediodorsal & 1.70 & 0.11 & 1.69 & 0.10 & 2.27 & 0.17 & 2.32 & 0.17 & 1.97 & 0.07 & 1.98 & 0.06 \\
\hline Lateral & 1.95 & 0.07 & 1.90 & 0.05 & 2.28 & 0.10 & 2.23 & 0.12 & 2.46 & 0.14 & 2.42 & 0.09 \\
\hline \multicolumn{13}{|l|}{ Hippocampus } \\
\hline CAl dorsal & 1.09 & 0.04 & 1.10 & 0.05 & 1.44 & 0.10 & 1.33 & 0.16 & 1.43 & 0.13 & 1.47 & 0.07 \\
\hline CA3 dorsal & 1.26 & 0.06 & 1.26 & 0.04 & 1.54 & 0.06 & 1.47 & 0.08 & 1.56 & 0.09 & 1.51 & 0.06 \\
\hline GD dorsal & 1.31 & 0.03 & 1.30 & 0.05 & 1.64 & 0.12 & 1.66 & 0.08 & 1.65 & 0.09 & 1.64 & 0.13 \\
\hline CAl ventral & 1.10 & 0.04 & 1.13 & 0.03 & 1.58 & 0.08 & 1.48 & 0.07 & 2.48 & 0.20 & 2.53 & 0.21 \\
\hline CA3 ventral & 1.27 & 0.05 & 1.27 & 0.05 & $1.88^{a}$ & 0.07 & 1.48 & 0.06 & 2.60 & 0.21 & 2.61 & 0.19 \\
\hline GD ventral & 1.33 & 0.04 & 1.36 & 0.04 & $3.47^{\mathrm{a}}$ & 0.12 & 1.56 & 0.06 & 2.95 & 0.24 & 2.75 & 0.12 \\
\hline \multicolumn{13}{|l|}{ Cortex } \\
\hline Anterior cingulate & 1.46 & 0.07 & 1.43 & 0.07 & 2.23 & 0.06 & 2.29 & 0.10 & 2.13 & 0.12 & 2.16 & 0.08 \\
\hline Posterior cingulate & 1.43 & 0.09 & 1.46 & 0.05 & 2.29 & 0.13 & 2.25 & 0.20 & 2.99 & 0.08 & 2.91 & 0.15 \\
\hline Lateral entorhinal & 1.18 & 0.04 & 1.15 & 0.05 & $1.67^{\mathrm{a}}$ & 0.12 & 1.09 & 0.07 & 1.49 & 0.17 & 1.45 & 0.13 \\
\hline Medial entorhinal & 1.18 & 0.07 & 1.19 & 0.04 & $1.82^{a}$ & 0.07 & 1.13 & 0.05 & 1.40 & 0.18 & 1.43 & 0.15 \\
\hline Frontal & 1.33 & 0.07 & 1.32 & 0.06 & 1.87 & 0.07 & 1.76 & 0.06 & 2.08 & 0.10 & 2.11 & 0.08 \\
\hline Parietal & 1.58 & 0.08 & 1.59 & 0.07 & 1.49 & 0.10 & 1.50 & 0.11 & 1.76 & 0.15 & 1.79 & 0.14 \\
\hline Pyriform & 1.71 & 0.09 & 1.72 & 0.06 & 2.38 & 0.14 & 2.19 & 0.09 & 2.43 & 0.09 & 2.40 & 0.12 \\
\hline
\end{tabular}

Note- $M$, mean; $S E M$, standard error of mean. Data presented in bold type represent significant differences in labeling intensity in stimulated animals as compared with unstimulated controls. a Ipsilateral stimulated side was more labeled than the contralateral stimulated side and more labeled than the ipsilateral side of unstimulated controls. b Ipsilateral stimulated side was more labeled only when compared with the ipsilateral side of unstimulated controls. 
Table 3

Relative 2-DG Uptake Following Lateral Entorhinal Cortex Stimulation

\begin{tabular}{|c|c|c|c|c|c|c|c|c|}
\hline \multirow[b]{4}{*}{ Structure } & \multicolumn{8}{|c|}{ LEC Stimulation } \\
\hline & \multicolumn{4}{|c|}{ Intact Animals } & \multicolumn{4}{|c|}{ Perforant-Path Lesioned } \\
\hline & \multicolumn{2}{|c|}{ Ipsi } & \multicolumn{2}{|c|}{ Contra } & \multicolumn{2}{|c|}{ Ipsi } & \multicolumn{2}{|c|}{ Contra } \\
\hline & $M$ & $S E M$ & $M$ & $S E M$ & $M$ & $S E M$ & $M$ & $S E M$ \\
\hline Amygdala & 3.90 & $0.23^{\mathrm{a}}$ & 1.35 & 0.10 & $1.84^{\text {bd }}$ & 0.17 & 1.01 & 0.11 \\
\hline Caudate Putamen & 2.20 & 0.09 & 2.19 & 0.10 & 1.99 & 0.10 & 1.92 & 0.08 \\
\hline Diagonal band & 3.84 & $0.14^{\mathrm{a}}$ & 2.14 & 0.11 & $2.80^{\mathrm{bd}}$ & 0.17 & 2.02 & 0.11 \\
\hline Lateral septum & 4.24 & $0.08^{a}$ & 1.58 & 0.05 & $2.75^{\text {bd }}$ & 0.15 & 1.42 & 0.07 \\
\hline Medial septum & 3.79 & 0.22 & 3.79 & 0.22 & $1.50^{\mathrm{c}}$ & 0.04 & 1.50 & $0.04^{\mathrm{c}}$ \\
\hline Mammillary bodies & 4.37 & 0.11 & 4.37 & 0.11 & $2.86^{\mathrm{c}}$ & 0.05 & 2.86 & $0.05^{\mathrm{c}}$ \\
\hline Stria terminalis & 2.08 & $0.11^{\mathrm{a}}$ & 1.02 & 0.06 & $1.32^{\mathrm{b}}$ & 0.14 & 1.03 & 0.08 \\
\hline Subiculum & 2.34 & 0.12 & 2.29 & 0.13 & $0.99 \mathrm{c}$ & 0.05 & 0.98 & $0.02^{c}$ \\
\hline \multicolumn{9}{|l|}{ Hypothalamus } \\
\hline Dorsomedial & 1.42 & 0.10 & 1.46 & 0.12 & 1.77 & 0.08 & 1.60 & 0.08 \\
\hline Lateral & 1.82 & 0.14 & 1.71 & 0.05 & 1.91 & 0.13 & 1.77 & 0.08 \\
\hline Ventromedial & 1.28 & 0.05 & 1.31 & 0.07 & 1.40 & 0.10 & 1.33 & 0.07 \\
\hline \multicolumn{9}{|l|}{ Thalamus } \\
\hline Anteromedial & 3.45 & 0.10 & 3.35 & 0.12 & $2.49^{c}$ & 0.11 & 2.25 & $0.18^{c}$ \\
\hline Mediodorsal & 2.99 & 0.10 & 3.08 & 0.12 & $2.27^{\mathrm{a}}$ & 0.10 & 2.28 & $0.08^{c}$ \\
\hline Lateral & 3.31 & 0.13 & 3.33 & 0.19 & $2.35^{\mathrm{c}}$ & 0.11 & 2.28 & $0.17^{\mathrm{c}}$ \\
\hline \multicolumn{9}{|l|}{ Hippocampus } \\
\hline CAl dorsal & 1.33 & 0.07 & 1.35 & 0.10 & 1.20 & 0.06 & 1.32 & 0.03 \\
\hline CA3 dorsal & 1.34 & 0.06 & 1.44 & 0.10 & 1.30 & 0.06 & 1.50 & 0.04 \\
\hline GD dorsal & 1.41 & 0.08 & 1.40 & 0.07 & 1.24 & 0.09 & 1.35 & 0.03 \\
\hline CAl ventral & 2.11 & $0.09^{\mathrm{a}}$ & 1.56 & 0.10 & $1.61^{\mathrm{b}}$ & 0.13 & 1.33 & 0.15 \\
\hline CA3 ventral & 3.65 & $0.11^{\mathrm{a}}$ & 1.66 & 0.09 & $2.08^{\text {bd }}$ & 0.27 & 1.39 & 0.13 \\
\hline GD ventral & 3.00 & $0.17^{a}$ & 1.46 & 0.06 & $2.01^{b d}$ & 0.19 & 1.33 & 0.07 \\
\hline \multicolumn{9}{|l|}{ Cortex } \\
\hline Anterior Cingulate & 2.68 & 0.11 & 2.66 & 0.05 & 2.24 & 0.19 & 2.38 & 0.15 \\
\hline Posterior Cingulate & 3.36 & 0.12 & 3.17 & 0.14 & 2.98 & 0.14 & 2.80 & 0.18 \\
\hline Lateral Entorhinal & 4.43 & $0.14^{\mathrm{a}}$ & 1.23 & 0.05 & $4.53^{\mathrm{d}}$ & 0.17 & 1.88 & 0.08 \\
\hline Medial Entorhinal & 4.31 & $0.16^{a}$ & 1.16 & 0.04 & $4.33^{\mathrm{d}}$ & 0.14 & 1.01 & 0.02 \\
\hline Frontal & 2.06 & 0.08 & 2.11 & 0.07 & 1.92 & 0.18 & 1.68 & 0.19 \\
\hline Parietal & 3.07 & 0.16 & 2.96 & 0.11 & 2.76 & 0.16 & 2.60 & 0.13 \\
\hline Pyriform & 3.89 & 0.14 & 3.16 & 0.12 & $2.42^{\mathrm{c}}$ & 0.10 & 2.31 & $0.12^{c}$ \\
\hline
\end{tabular}

Note--Relative 2-DG uptake for the various structures is expressed as $M \pm S E M$. Structures in italic script were significantly bilaterally more labeled in intact stimulated animals than in unstimulated con-

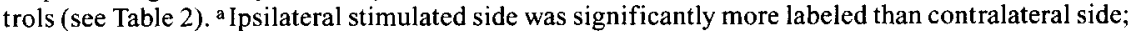
bsignificant labeling decrease in ipsilateral side of structures of lesioned animals compared with intact stimulated animals; ${ }^{c}$ significant bilateral labeling decrease in lesioned animals compared with intact stimulated animals; ${ }^{\mathrm{d}}$ significantly greater ipsilateral labeling within lesioned animals.

\section{RESULTS}

The quantitative data for unstimulated, MS-stimulated, and DMH-stimulated animals are presented in Table 2, and in Table 3 for LEC-stimulated animals and LECstimulated animals with a unilateral perforant-path lesion.

\section{Effects of MS Stimulation}

Figure 1 presents the major labeling increases observed after unilateral MS stimulation. Statistical analysis (see Table 2) showed that such stimulation produced bilateral increases in labeling in the amygdala, diagonal band, lateral and medial septum, mammillary bodies, stria terminalis, subiculum, lateral hypothalamus (medial forebrain bundle), anteromedial thalamus, hippocampus (ventral $\mathrm{CA} 1, \mathrm{CA} 3$, and GD), anterior and posterior cingulate cortices, and frontal and pyriform cortices. A small but significant increase of labeling was also observed in the contralateral lateral thalamic nucleus.

\section{Effects of DMH Stimulation}

Figure 2 presents the 2-DG labeling observed in DMHstimulated animals. The statistical analysis (see Table 2) revealed that unilateral electrical stimulation of the DMH produced bilateral increases in labeling in subcortical structures (caudate nucleus, lateral septum, mammillary bodies, anteromedial and mediodorsal thalamic nuclei) and in cortical structures (cingulate, frontal, and pyriform cortices). Unilateral labeling increases on the stimulated side were observed in the hypothalamus (dorsomedial, lateral, and ventromedial nuclei), in the amygdala, diagonal band, lateral septum, stria terminalis, hippocampus (ventral CA3 and GD), and lateral and medial entorhinal cortices.

\section{Effects of LEC Stimulation}

Figure 3 presents the major labeling increases observed after unilateral LEC stimulation. The statistical analysis (see Table 3) showed that, compared with unstim- 


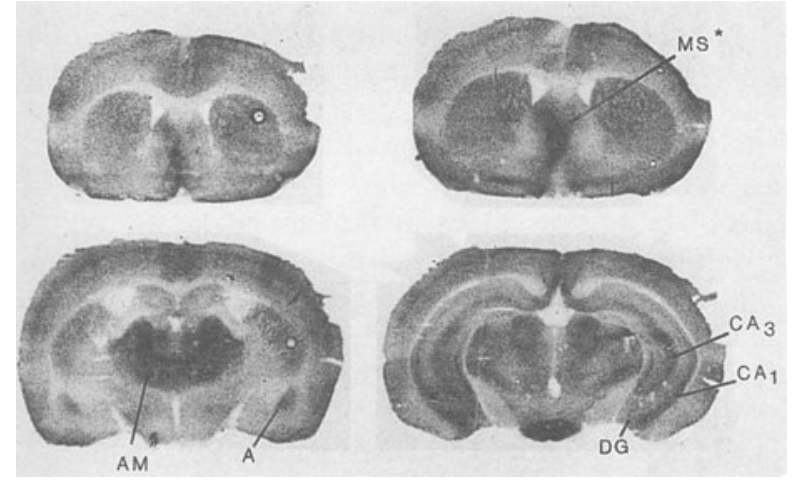

Figure 1. $\left({ }^{14} \mathrm{C}\right) 2-\mathrm{DG}$ autoradiographs of coronal brain sections showing the distribution of 2-DG labeling following MS stimulation. Note in particular the increases in 2-DG labeling in the amygdala (A), anteromedial thalamus (AM), and hippocampal formation (CA1, CA3, and DG). MS* indicates the location of the stimulating electrode in the MS.

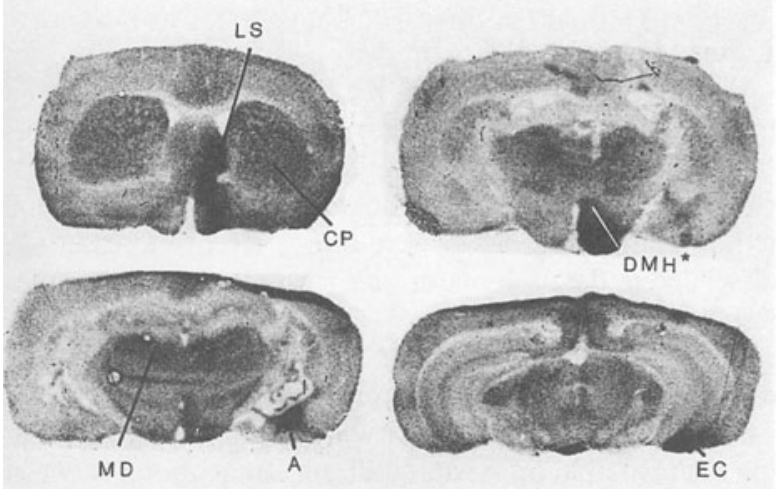

Figure 2. ( $\left.{ }^{14} \mathrm{C}\right) 2-D G$ autoradiographs of coronal brain sections showing the distribution of 2-DG labeling following unilateral DMH stimulation. Note in particular the increases in 2-DG labeling in the lateral septum (LS), caudate putamen (CP), amygdala (A), mediodorsal thalamus (MD), and entorhinal cortex (EC). DMH* indicates the location of the stimulating electrode in the DMH.

ulated animals, unilateral LEC stimulation produced bilateral labeling increases in the caudate putamen, diagonal band, medial septum, mammillary bodies, subiculum, lateral hypothalamus, thalamus (anteromedial, mediodorsal, and lateral), anterior and posterior cingulate cortices, and frontal and pyriform cortices. Moreover, LEC stimulation produced relatively greater increases in ipsilateral labeling in the amygdala, diagonal band, lateral septum, stria terminalis, hippocampus (ventral CA3 and GD), and lateral and medial entorhinal cortices.

\section{Effects of Perforant-Path Lesions on}

\section{LEC-Stimulation-Induced 2-DG Labeling Patterns}

Statistical analysis (see Table 3 ) showed that, compared with unlesioned LEC-stimulated animals, perforant-pathlesioned animals showed a large decrease in the labeling intensity bilaterally in the medial septum, mammillary bodies, subiculum, thalamus (anteromedial, mediodorsal, and lateral), and pyriform cortex. There was also a de- crease in ipsilateral labeling intensity in the amygdala, diagonal band, lateral septum, stria terminalis, and CA1, $\mathrm{CA} 3$, and GD ventral hippocampal regions. In contrast, the regional 2-DG labeling increases due to stimulation of the LEC persisted in the cingulate, medial entorhinal, frontal, and parietal cortices. When the ipsi- and contralateral sides were compared within the lesioned animals, labeling intensity was found to be relatively greater in the ipsilateral amygdala, diagonal band, lateral septum, and hippocampus (ventral CA3 and GD).

\section{DISCUSSION}

Table 4 summarizes the major results of the present study. In the first part of this discussion section, the global patterns of metabolic activation observed following the stimulation of the MS, the DMH, and the LEC will be compared and discussed. Following that, we will discuss the implications of our data in the context of putative neural networks involved in the spatiotemporal evolution of memory processes in the brain.

\section{Medial Septum}

Electrical stimulation of the MS produced significant increases in 2-DG labeling in many subcortical structures and in the whole ventral hippocampal formation (CA1, CA3, and DG). It is particularly noticeable that we observed only slight labeling in the hypothalamus (except the medial forebrain bundle) and thalamus (except the anteromedial nucleus), while no labeling increases at all were observed in the entorhinal or parietal cortices. Globally, these data are consistent with those obtained in rats by Watson et al. (1985), using the same relative 2-DG method (except for the fact that Watson et al. did not observe any significant labeling in the hippocampus - a finding which is at variance with the well-known anatomical connections between these struc-

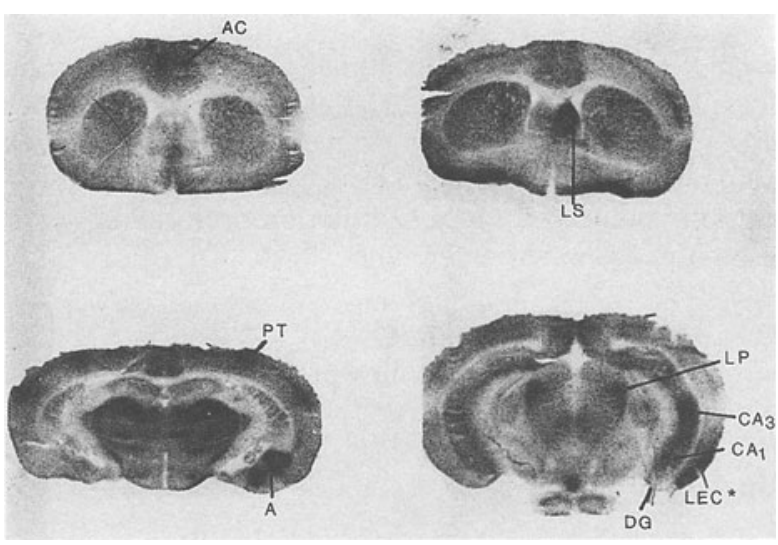

Figure 3. $\left({ }^{14} \mathrm{C}\right) 2$-DG autoradiographs of horizontal brain sections showing the distribution of 2-DG labeling following unilateral LEC stimulation. Note in particular the increases in 2-DG labeling in the anterior cingulate cortex (AC), lateral septum (LS), amygdala (A), parietal cortex (PT), lateral posterior thalamus (LP), and hippocampal regions (CA1, CA3, and DG). $L E C$ * indicates the location of the stimulating electrode in the LEC. 
Table 4

Main Effects of Electrical Stimulation of the

MS, DMH, and LEC on Relative 2-DG Uptake

\begin{tabular}{|c|c|c|c|c|}
\hline \multirow[b]{3}{*}{ Structure } & \multicolumn{4}{|c|}{ Area of Stimulation } \\
\hline & \multirow[b]{2}{*}{ MS } & \multirow[b]{2}{*}{$\mathrm{DMH}$} & \multicolumn{2}{|c|}{ LEC } \\
\hline & & & Nonlesioned & $\begin{array}{c}\begin{array}{c}\text { Perforant-Path } \\
\text { Lesioned }\end{array} \\
\end{array}$ \\
\hline Amygdala & + & + & + & $+(\mathrm{i})$ \\
\hline Caudate putamen & & + & + & + \\
\hline Diagonal band & + & + & + & $+(i)$ \\
\hline Lateral septum & + & + & + & $+(\mathrm{i})$ \\
\hline Medial septum & + & & & \\
\hline Mammillary bodies & + & + & + & \\
\hline Stria terminalis & + & + & + & \\
\hline Subiculum & + & + & + & \\
\hline \multicolumn{5}{|l|}{ Hypothalamus } \\
\hline Dorsomedial & & + & & \\
\hline Lateral & + & + & + & + \\
\hline \multirow{2}{*}{\multicolumn{5}{|c|}{ Thalamus }} \\
\hline & & & & \\
\hline Anteromedial & + & + & + & + \\
\hline Mediodorsal & & + & + & + \\
\hline Lateral & & & + & + \\
\hline \multicolumn{5}{|l|}{ Hippocampus } \\
\hline \multicolumn{5}{|l|}{ CA1 dorsal } \\
\hline \multirow{2}{*}{\multicolumn{5}{|c|}{$\begin{array}{l}\text { CA3 dorsal } \\
\text { GD dorsal }\end{array}$}} \\
\hline & & & & \\
\hline CAl ventral & + & & + & \\
\hline CA3 ventral & + & + & + & $+(\mathrm{i})$ \\
\hline GD ventral & + & + & + & $+(\mathrm{i})$ \\
\hline \multicolumn{5}{|l|}{ Cortex } \\
\hline Anterior cingulate & + & + & + & + \\
\hline Posterior cingulate & + & + & + & + \\
\hline Lateral entorhinal & & + & + & + \\
\hline Medial entorhinal & & + & + & + \\
\hline Frontal & + & + & + & + \\
\hline Parietal & & & + & + \\
\hline Pyriform & + & + & + & + \\
\hline
\end{tabular}

Note-_+ indicates significant labeling increases as a consequence of MS, DMH, or LEC stimulation. In perforant-path-lesioned, LECstimulated brains, (i) indicates a significantly greater ipsilateral labeling on the stimulated side. Stimulated structures are indicated in italics.

tures [i.e., the septo-hippocampal pathway; Meibach \& Siegel, 1977; Swanson, 1978]; this discrepancy might be explained by the fact that Watson et al. used anesthetized animals. In summary, it can be concluded that the 2-DG patterns induced by MS stimulation preferentially engage hippocampal-centered networks.

\section{Dorsomedial Hypothalamus}

The pattern of 2-DG labeling produced by stimulation of the DMH differed from that induced by MS stimulation in that (1) it produced significant increases in 2-DG labeling in the striatum (caudate-putamen), the whole hypothalamic area (dorsomedial, lateral, and ventromedial regions), and the mediodorsal thalamus, and also in the entorhinal cortex, which is consistent with a reported direct connection between this region and the DMH (Wyss, 1981); (2) no labeling increase was observed in the MS, a result which is consistent with the data of Watson et al. (1982); (3) the 2-DG labeling in the ventral hippocampus was restricted to the $\mathrm{CA} 3$ and the dentate gyrus; and (4) a very large increase in labeling was observed in the amygdala (see Figure 2 for an example), an increase that has also been more recently described by Maxwell and Fink (1988) after stimulation of the anterior hypothalamic area in female rats (it is very likely that in fact, these 2-DG-labeling increases in the amygdala, as well as those observed in the lateral septum and the ventral hippocampus, are due to the activation of the ventromedial hypothalamic and medial preoptic areas, which are highly interconnected with the DMH [Luiten \& Room, 1980]). From these results, it can be concluded that the 2-DG patterns induced by DMH stimulation involved a great number of subcortical and cortical structures which are connected by mono- or polysynaptic pathways and stimulated ortho- or antidromically. However, the lack of 2-DG labeling in the MS and the restricted labeling in the ventral hippocampus indicate that the influence of DMH stimulation is probably not mediated by the septo-hippocampal pathway.

\section{Lateral Entorhinal Cortex}

The patterns of cerebral metabolic changes induced by LEC stimulation and their modifications after perforant-path lesions are original observations. Table 4 shows that, except for the dorsal hippocampus and the hypothalamic regions (where only a slight increase was observed in the medial-forebrain bundle), LEC stimulation increased the relative 2-DG uptake in all subcortical regions, thalamic regions (where the lateral nucleus, too, presented a 2-DG labeling), and cortical regions. These results are consistent with the literature describing the principal direct and indirect connections between the entorhinal cortex and the hippocampus, as well as between the entorhinal cortex and the other subcortical and cortical areas. (For an exhaustive review of these connections, see Lopes Da Silva, Witter, Boeijinga, \& Lohman, 1990.) However, it should be observed that no 2-DG-labeling increases were induced in the dorsal hippocampus, even though direct or indirect (via the lateral septum) connections between the entorhinal cortex and the dorsal hippocampal regions have been described in the rat.

\section{Effects of Perforant-Path Lesions}

Perforant-path lesion results in the disappearance of entorhinal-stimulation-induced labeling in the CA1 region of the ventral hippocampus and in a large reduction in labeling in the $\mathrm{CA} 3$ and dentate regions. On the other hand, labeling increases persist ipsilaterally to the stimulated side in the amygdala, the diagonal band, the lateral septum, the thalamus nuclei, and, finally, the cortical areas (parietal, cingulate, and frontal). These results suggest that the following three functionally distinct anatomical systems are involved in the present observations. First, the very large reduction of hippocampal activation after lesion of the perforant pathway confirms the view, based on anatomical data (Amaral \& Witter, 1989), that the entorhinal cortex is a major source of input to the hippocampal formation. Second, and more inter- 
estingly, the persistence, following perforant-path lesions, of the labeling observed in the amygdala, thalamus, diagonal band, lateral septum, and frontal cortex indicates that entorhinal stimulation could activate a hippocampal-independent amygdalofugal pathway, linking the amygdala to the thalamus and the frontal cortexan interpretation supported by anatomical and physiological data (Brothers, 1985). The residual weak labeling in the ventral hippocampus following perforant-path transection could then be due to an antidromic activation exerted by this polysynaptic circuit back onto the hippocampal formation via a ventral pathway that forms a relay in the amygdala (Poletti, Kliot, \& Boytim, 1984). Third, the persistence of neocortical labeling in the cingulate, parietal, and frontal areas suggests that entorhinal stimulation also triggers activation of direct corticocortical pathways (Kosel, Van Hoesen, \& Rosene, 1982; Sorensen, 1985) which would exist independently of the hippocampus.

\section{Relation of the Present Data to the Neural Pathways Involved in Memory Processes}

The present study is to be viewed as a complement to a larger group of studies we have previously conducted that revealed, on the one hand, memory-enhancing effects of electrical stimulation of limbic structures, and on the other, 2-DG metabolic changes following behavioral training. We are, of course, aware that the structures we selected in the present study are not involved solely in memory processing; they are certainly also involved in other brain functions. It is also clear that 2-DG changes induced by electrical stimulation of these structures cannot be conceived of as mimicking memory functioning, and that brain-mapping techniques do not solely identify regions specifically activated during a memory task. Nevertheless, the present results provide further insights into the putative neuronal substrates involved in early and late memory processes. Briefly, in a first set of studies (see the Introduction), we showed that, following a partial-acquisition session involving a barpressing appetitive task, electrical stimulation of various structures produced time-dependent memory-enhancing effects. The time gradient of efficacy for the stimulation differed as a function of the structures. In a second series of studies, we investigated the modifications of 2-DG uptake that were induced by different learning tasks at different times following the end of training in normal unstimulated mice (Bontempi et al., 1991; Destrade et al., 1992; Sif et al., 1991). This second series demonstrated that early stages of memory processes and consolidation are specifically associated with immediate posttraining increases in the relative metabolic activity in the septum and diagonal band, as well as in the hippocampus, anterior thalamus, and mammillary bodies. In contrast, late memory stages are associated with delayed increases (by up to $3 \mathrm{~h}$ ) in relative metabolic activity in such cortical regions as the frontal, cingulate, parietal, and lateral entorhinal areas. Metabolic activation in the hypothalamus was not found to be specifically linked to learning; that is, it was also observed in active control animals. These data supported the hypothesis that there are early and late memory processes which specifically involve different brain circuits in a sequentially organized manner.

In the present study, we investigated the 2-DG changes produced by electrical stimulation of three structures. It cannot be determined as yet whether stimulation in mice tested in learning/memory tasks could possibly result in a 2-DG uptake pattern sensibly different from the present effects found in behaviorally naive mice. Preliminary data obtained in the course of previous experiments (Sif, Bontempi, Messier, \& Destrade, 1990) indicated that in the MS, posttraining stimulation in trained mice yielded patterns of increased 2-DG labeling that were qualitatively similar to those observed in the present study in nontrained mice. Thus, the interpretations of the different brain circuits engaged in the various timedependent phases of memory processing proposed in the following paragraphs must be considered somewhat speculative until the systematic verification, currently under way, of the patterns of increased 2-DG labeling between stimulated nontrained and stimulated trained groups of mice has been completed.

Nevertheless, comparing structures showing increased 2-DG labeling after MS stimulation (effective on memory for less than $10 \mathrm{~min}$ ) with those showing increased 2-DG labeling after DMH stimulation (effective on memory for $1 \mathrm{~h}$ after training), we observe that the former, but not the latter, produces increased 2-DG labeling in the ventral CA1 hippocampal region and that, accordingly, the labeling in the other hippocampal fields is generally greater after MS stimulation than it is after DMH stimulation. Globally, DMH stimulation produces a more widespread brain metabolic activation than MS stimulation; for example, it induces 2-DG labeling increases in the striatum (caudate and putamen), mediodorsal thalamus, and several cortical areas, including the lateral and medial entorhinal cortices, none of which are observed following stimulation of the MS.

The specific labelings produced by MS stimulation in the CA1 region and in the whole extent of the ventral hippocampus strengthen the hypothesis, already proposed by several authors (see Dunnett, 1985; Eichenbaum, Otto, \& Cohen, 1992; Jaffard \& Meunier, 1993; Rawlins, 1985), that the MS intimately belongs to a hippocampalcentered system critically involved in the early stage of memory formation. The lack of 2-DG changes induced by $\mathrm{DMH}$ stimulation in the septum and hippocampus, or the weakness of those that do occur, implies that the memory-enhancing effect of DMH stimulation is very unlikely to be mediated by the septo-hippocampal system. Because DMH stimulation yields 2-DG activation in a large array of other subcortical and cortical structures, one can speculate that the memory-enhancing effect of DMH stimulation at both early and late memory stages could reflect an undifferentiated activation of several nonhippocampal subcortical and cortical pathways. Such a view could account for the fact that, in unstimulated trained animals (Bontempi et al., 1991; Sif et al., 
1991), no learning-specific 2-DG increases were observed in the hypothalamus.

Although it induces an activation of the septohippocampal system that is assumed to be critically implicated in early memory processes, stimulation of the entorhinal cortex does not enhance learning performance when applied at short posttraining intervals. While these data may seem contradictory, they are, however, consistent with recent behavioral studies which demonstrated that although it provides a major source of sensory input to the hippocampus (and, to a lesser extent, to the amygdala), the entorhinal cortex plays an important role by itself in some memory functions, and that this role is different from that of the hippocampus proper (e.g., Meunier, Bachevalier, Mishkin, \& Murray, 1993; Otto \& Eichenbaum, 1992; Zola-Morgan, Squire, Amaral, \& Suzuki, 1989). Recent investigations of the effects of selective (neurotoxic) entorhinal lesions indeed indicate that, in contrast to the hippocampus, the entorhinal cortex would contribute predominantly to late memory processes (Cho, Béracochea, \& Jaffard, 1993; Levisohn \& Isaacson, 1991; Myhrer, 1989). Unlike MS stimulation, entorhinal-cortex stimulation produces a large amount of cortical activation, and, in particular, specific activation of the parietal cortex, a structure which also makes an important contribution to memory processing (Kesner, 1991, 1993; Kesner \& Di Mattia, 1984). Interestingly, this cortical labeling is spared following transection of the perforant path. Taken together, these results thus suggest that the delayed (by between 15 and $60 \mathrm{~min}$ ) memoryenhancing effect of posttraining electrical stimulation of the entorhinal cortex could be mediated mainly by cortical pathways, independently of the hippocampus, and that it is involved in the long-term storing of information.

\section{REFERENCES}

Amaral, D. G., \& Witter, M. P. (1989). The three-dimensional organization of the hippocampal formation: A review of anatomical data. Neuroscience, 31, 571-591.

BERMAN, R. F. (1991). Electrical brain stimulation used to study mechanisms and models of memory. In J. L. Martinez \& R. P. Kesner (Eds.), Learning and memory: A biological view (2nd ed., pp. 409438). San Diego: Academic Press.

BLOCH, V. (1970). Facts and hypotheses concerning memory consolidation processes. Brain Research, 24, 561-575.

Bontempi, B., Sif, J., JAFFard, R., \& Destrade, C. (1991). Analyse par le $\left({ }^{14} \mathrm{C}\right)$ glucose de la cinétique des activations métaboliques cérébrales consécutives à l'apprentissage d'une discrimination spatiale dans un labyrinthe radial à huit bras chez la souris. Comptes Rendus de l'Académie des Sciences, 313, 195-200.

Brothers, L. A. (1985). Physiological evidence for an excitatory pathway from entorhinal cortex to amygdala in the rat. Brain Research, 359, $10-20$.

Brutus, M., Watson, R. E., Jr., Shaikh, M. B., Siegel, H. E., WEINER, S., \& SiEgEL, A. (1984). A $\left({ }^{14} \mathrm{C}\right) 2$-deoxyglucose analysis of the functional neural pathways of the limbic forebrain in the rat: IV. A pathway from the prefrontal cortical-medial thalamic system to the hypothalamus. Brain Research, 310, 279-293.

Catarelli, M., Astic, L., \& Kauer, J. S. (1989). Metabolic mapping of 2-deoxyglucose uptake in the rat pyriform cortex using computerized image processing. Brain Research, 442, 180-184.

CHO, Y., BéRACOCHEA, D., \& JAFFARD, R. (1993). Extended temporal gradient for the retrograde and anterograde amnesia produced by ibotenate entorhinal cortex lesions in mice. Journal of Neuroscience, 13, 1759-1766.

Destrade, C. (1982). Two types of diencephalically driven RSA (theta) as a means of studying memory formation in mice. Brain Research, 234, 486-493.

Destrade, C., Gauthier, M., \& SiF, J. (1985). Sequential intervention of different limbic structures in memory processes. In B. E. Will, P. Schmitt, \& J. C. Dalrymple-Alford (Eds.), Brain plasticity, learning and memory (pp. 183-192). New York: Plenum.

Destrade, C., Messier, C., Bontempi, B., Sif, J., \& Jaffard, R. (1992). Investigations into time-dependent metabolic changes during memory processing in the mouse brain using $\left({ }^{14} \mathrm{C}\right)$-deoxyglucose and $\left({ }^{14} \mathrm{C}\right)$-glucose. In F. Gonzalez-Lima (Ed.), Advances in metabolic mapping techniques for brain imaging of behavioral and learning functions (pp. 389-407). Dordrecht: Kluver.

DuNN, A. J. (1986). Biochemical correlates of learning and memory. In J. L. Martinez, Jr., \& R. P. Kesner (Eds.), Learning and memory: A biological view (pp. 165-201). New York: Academic Press.

DuNNETT, S. B. (1985). Comparative effects of cholinergic drugs and lesions of nucleus basalis or fimbria-fornix on delayed matching in rats. Psychopharmacology, 87, 357-363.

Eichenbaum, H., Otto, T., \& Cohen, N. J. (1992). The hippocampus: What does it do? Behavioral \& Neural Biology, 57, 2-36.

GALEY, D., \& JAFFARD, R. (1992). Post-training medial septal stimulation improves spatial information processing in BALB/c mice. Neuroscience Letters, 143, 87-90.

Galey, D., Jeantet, Y., Destrade, C., \& JafFard, R. (1983). Facilitation of memory consolidation by post-training electrical stimulation of the medial septal nucleus: Is it mediated by changes in rhythmic slow activity? Behavioral \& Neural Biology, 38, 240-250.

Gauthier, M., \& Destrade, C. (1984). Late post-learning effect of entorhinal cortex electrical stimulation persists despite destruction of the perforant path. Brain Research, 310, 174-179.

Gauthier, M., Destrade, C., \& Soumikeu-Mourat, B. (1982). Late post-learning participation of entorhinal cortex in memory processes. Brain Research, 233, 255-264.

Glickman, S. E. (1961). Perseverative neural processes and consolidation of the memory trace. Psychological Bulletin, 58, 218-233.

GoLD, P. E., \& MCGAUGH, J. L. (1975). A single trace two process view of memory storage processes. In D. Deutsch \& J. A. Deutsch (Eds.), Short-term memory (pp. 355-378). New York: Academic Press.

Gold, P. E., ZoRneTzer, S. F., \& MCGAUGH, J. L. (1974). Electrical stimulation of the brain: Effects on memory storage. In G. Newton \& A. H. Riesen (Eds.), Advances in psychobiology (Vol. 2, pp. 193224). New York: Wiley.

Gonzalez-Lima, F. (1989). Functional brain circuitry related to arousal and learning in rats. In J. P. Ewert \& M. A. Arbid (Eds.), Visuomotor coordination (pp. 729-765). New York: Plenum.

Gonzalez-Lima, F., FinkenstaedT, T., \& EwERT, J. P. (1989). Learning-related activation in the auditory system of the rat produced by long-term habituation: A 2-deoxyglucose study. Brain Research, 489, 67-79.

HEBB, D. O. (1949). The organization of behavior. New York: Wiley. Horster, W., Rivers, A., Schuster, B., Ettlinger, G., SkreCZEZ, W., \& HESSE, W. (1989). The neural structures involved in crossmodal recognition and tactile discrimination performance: An investigation using 2-DG. Behavioural Brain Research, 33, 209-227.

Huston, J. P., Mueller, C., \& Mondadori, C. (1977). Memory facilitation by post-trial hypothalamic stimulation and other reinforcers: A central theory of reinforcement. Biobehavioral Reviews, 1, 143-150.

IzQUIERDO, I. (1989). Different forms of post-training memory processing. Behavioral \& Neural Biology, 651, 171-202.

JAFFARD, R., \& MEUnier, M. (1993). Role of the hippocampal formation in learning and memory. Hippocampus, 3, 203-218.

KESNER, R. P. (1982). Brain stimulation: Effects on memory. Behavioral \& Neural Biology, 36, 315-367.

KESNER, R. P. (1991). Neurobiological views of memory. In J. L. Martinez, Jr. \& R. P. Kesner (Eds.), Learning and memory: A biological view (pp. 499-547). New York: Academic Press.

Kesner, R. P. (1993). Paired associate learning in the rat: Role of 
hippocampus, medial prefrontal cortex, and parietal cortex. Psvchobiology, 21, 183-192.

Kesner, R. P., \& Dimattia, B. V. (1984). Posterior parietal association cortex and hippocampus: Equivalency of mnemonic function in animals and humans. In L. R. Squire \& N. Butters (Eds.), Neuropsychology of memory (pp. 385-398). New York: Guilford.

KeSNER, R. P., \& WiLbURN, M. W. (1974). A review of electrical stimulation of the brain in context of learning and retention. Behavioral Biology, 10, 259-293.

Kosel, K. C., Van Hoesen, G. W., \& Rosene, D. L. (1982). Nonhippocampal cortical projections from the entorhinal cortex in the rat and rhesus monkey. Brain Research, 244, 201-213.

Lehman, A. (1974). Atlas stéréotaxique du cerveau de la souris. Paris: Editions du CNRS.

LeVISOHN, L. F., \& ISAACSON, O. (1991). Excitotoxic lesions of the rat entorhinal cortex: Effects of selective neuronal damage on acquisition and retention of a non-spatial reference memory task. Brain Re search, 564, 230-244.

Lopes Da Silva, F. H., Witter, M. P., Boeijinga, P. H., \& Lohman, A. H. M. (1990). Anatomic organization and physiology of the limbic cortex. Physiological Review, 70, 453.

Luiten, P. G., \& Room, P. (1980). Interrelations between lateral, dorsomedial and ventromedial hypothalamic nuclei in the rat. A HRP study. Brain Research, 190, 321-332.

Matsunami, K., Kawashima, T., \& Satake, H. (1989). Mode of $\left({ }^{14} \mathrm{C}\right) 2$-deoxy-D-glucose uptake into retrosplenial cortex and other memory-related structures of the monkey during a delayed response. Brain Research Bulletin, 22, 829-838.

MaXwell, R. C., \& FinK, G. (1988). The patterns of $\left({ }^{14} \mathrm{C}\right) 2$-deoxyglucose uptake in female rat produced by electrical stimulation of hypothalamic and limbic brain areas. Neuroscience, 24, 241-263.

MCGAUGH, J. L. (1966). Time-dependent processes in memory storage. Science, 153, 1351-1358.

Meibach, R. C., \& Siegel, A. (1977). Efferent connections of the septal area in the rat: An analysis utilizing retrograde and anterograde transport methods. Brain Research, 119, 1-20.

Meunier, M., Bachevalier, J., Mishkin, M., \& Murray, E. A. (1993). Effects on visual recognition of combined and separate ablations of the entorhinal and perirhinal cortex in rhesus monkeys. Journal of Neuroscience, 13, 5418-5432.

MYHRER, T. (1989). Retroactive memory of a visual discrimination task in the rat: Role of temporal-entorhinal cortices and their connections. Experimental Brain Research, 84, 517-524.

Otto, T., \& Eichenbaum, H. (1992). Complementary roles of the orbital prefrontal cortex and the perirhinal-entorhinal cortices in odor-guided delayed-nonmatching-to-sample task. Behavioral Neuroscience, 106, 762-775.

Poletti, C. E., Kliot, M., \& Boytim, M. (1984). Metabolic influence of the hippocampus on hypothalamus, preoptic and basal forebrain is exerted through amygdalofugal pathway. Neuroscience Letters, 45, 211-216.

Porrino, L. J., \& Crane, A. M. (1990). Metabolic mapping of the effects of drugs of abuse with the $2-\left({ }^{14} \mathrm{C}\right)$-deoxyglucose method. In Modern methods in pharmacology: Vol. 6. Testing and evaluation of drugs of abuse (pp. 147-164). New York: Wiley-Liss.

RaWlins, J. N. P. (1985). Associations across time: The hippocampus as a temporary memory store. Behavioral Brain Science, 8, 479-496.

ROUTTENBERG, A. (1975). Significance of intracranial self-stimulation pathways for memory consolidation. In P. B. Bradley (Ed.), Methods in brain research (pp. 453-474). London: Wiley.

SARTER, M., BODEWITZ, G., \& STECKLER, T. (1989). 2-( $\left.{ }^{3} \mathrm{H}\right)$-deoxyglucose uptake patterns in rats exploring a six-arm radial tunnel maze: Differences between experienced and non-experienced rats. Behavioral Neuroscience, 103, 1217-1225.

Sharp, F. R., Kilduff, T. S., Bzoegchami, S., Heller, H. C., \& Ryan, A. F. (1983). The relationship of local cerebral glucose utilization to optical density ratios. Brain Research, 263, 97-103.

Sif, J., Bontempi, B., Messier, C., \& Destrade, C. (1990). Effects of learning and post-training septal electrical stimulation on brain metabolic activity. European Journal of Neuroscience, Suppl. 3, p. 147.

Sif, J., Messier, C., Meunier, M., Bontempi, B., Calas, A., \& DeSTRADE, C. (1991). Time-dependent sequential increases in $\left({ }^{14} \mathrm{C}\right) 2-$ deoxyglucose uptake in subcortical and cortical structures during memory consolidation of an operant training in mice. Behavioral \& Neural Biology, 56, 43-61.

Sif, J., Meunier, M., Messier, C., Calas, A., \& Destrade, C. (1989). Quantitative $\left({ }^{14} \mathrm{C}\right) 2$-deoxyglucose study of a functional dissociation between anterior and posterior cingulate cortices in mice. Neuroscience Letters, 101, 223-228.

Sokoloff, L., Reivich, M., Kennedy, C., Des Rosiers, M. H., Patlak, C. S., Pettigrew, K. D., Sakurada, O., \& Shimohara, M. (1977). The $\left({ }^{14} \mathrm{C}\right)$-deoxyglucose method for measurement of local cerebral glucose utilization: Theory, procedure and normal values in the conscious and anesthetized albino rat. Journal of Neurochemistry, 28 , 897-916.

SoRensen, K. E. (1985). Projection of the entorhinal area to the striatum, nucleus accumbens and cerebral cortex in the guinea pig. Journal of Comparative Neurology, 238, 308-322.

SQUIRE, L. R. (1987). Memory and brain. Oxford: Oxford University Press.

Swanson, L. W. (1978). The anatomical organization of septohippocampal projections. In K. Elliot \& J. Whelan (Eds.), Functions of the septo-hippocampal system (Ciba Foundation Symposium 58 , pp. 25-48). Amsterdam: Elsevier.

Watson, R. E., JR., Edinger, H. M., \& Siegel, A. (1983). A ( ${ }^{14}$ C)-2deoxyglucose analysis of the functional neural pathways of the limbic forebrain in the rat: III. The hippocampal formation. Brain Research Reviews, 5, 133-176.

Watson, R. E., JR., Siegel, H. E., \& Siegel, A. (1985). A $\left({ }^{14}\right.$ C)2deoxyglucose analysis of the functional neural pathways of the limbic forebrain in the rat. V. The septal area. Brain Research, 346, 9-107.

Watson, R. E., JR., Troiano, R., Poulakos, J., Weiner, S., Block, C. H., \& SiEGEL, A. (1983). A ( $\left.{ }^{14} \mathrm{C}\right) 2$-deoxyglucose analysis of the functional neural pathways of the limbic forebrain in the rat: $I$. The amygdala. Brain Research Reviews, 5, 1-44.

Watson, R. E., JR., Troiano, R., Poulakos, J., Weiner, S., \& SIEGEL, A. (1982). A $\left({ }^{14} \mathrm{C}\right)$-2-deoxyglucose analysis of the functional neural pathways of the limbic forebrain in the rat: 11 . The hypothalamus. Brain Research Bulletin, 8, 459-476.

WYSS, J. M. (1981). An autoradiographic study of the efferent connections of the entorhinal cortex in the rat. Journal of Comparative Neurology, 199, 495-512.

Zola-Morgan, S., Squire, L. R., Amaral, D. G., \& Suzuki, W. A. (1989). Lesions of the perirhinal and parahippocampal cortex that spare the amygdala and hippocampal formation produce severe memory impairment. Journal of Neuroscience, 9, 4355-4370.

(Manuscript received April 14, 1994; revision accepted for publication October 6,1994 .) 